\title{
HISTÓRIA NA BASE NACIONAL COMUM CURRICULAR: DÉJÀ VU E NOVOS DILEMAS NO SÉCULO XXI
}

\author{
HISTORY IN THE NATIONAL GENERAL CURRICULAR BASIS: DÉJÀ VU AND NEW \\ DILEMMAS IN THE $21^{\text {st }}$ CENTURY
}

Jean Carlos Moreno ${ }^{1}$

\begin{abstract}
RESUMO: O presente artigo é fruto da mesa redonda "Base Nacional Comum Curricular", realizada na abertura da III Jornada Paranaense PIBID/PET de História, na Universidade Estadual de Londrina (UEL), no dia 27 de novembro de 2015. O debate teve por objetivo contextualizar o processo de discussão da Base Nacional e tecer considerações a respeito do texto preliminar apresentado ao público em setembro de 2015. O texto preliminar, neste artigo e na mesa redonda, foi analisado do ponto de vista da seleção de conteúdos, da progressão, dos conceitos e da concepção de aprendizagem, buscando reforçar o papel do Ensino de História como mediador semiótico dos juízos morais que, situados socioculturalmente, orientam as ações humanas no mundo.
\end{abstract}

Palavras chave: BNCC. Currículo. Ensino de História.

\begin{abstract}
The current paper is the result of a debate between field researchers which is named "National General Curricular Basis" that happened in the III Paraná's History Journey PIBID/PET opening in the Universidade Estadual de Londrina (UEL) on November 27 2015. The debate aimed to contextualize the discussion process of the National Basis and weave thoughts about the previous text presented to the public in September 2015. The previous text was analyzed in this paper and in the debate from the point of view of content selection, progression, concepts and learning conception, whose search reinforces the role of History Teaching as a semiotic intermediate of moral judgments that guide the human actions in the world when socioculturally situated.
\end{abstract}

Keywords: BNCC. Curriculum. History teaching.

1 Professor Adjunto do Colegiado de História da UENP. Doutor em História pela UNESP. jeanmoreno@uenp.edu.br 
Em meados dos anos 1980, ao emergir de uma ditadura, cujo objetivo de impedir o amadurecimento das reflexões sociais dentro e fora do ambiente escolar era explícito, a sociedade brasileira pôs-se a revisar e reconstruir os seus programas curriculares para torná-los próprios a um ambiente democrático que se almejava reconstruir. Com a vitória da oposição em grande parte dos governos estaduais, as Secretarias de Educação assumem este papel em conjunto com professores universitários.

Um exemplo significativo destas ações está na construção da proposta do estado de São Paulo, que é uma das mais estudadas pela pesquisa acadêmica até o momento, tanto pelo papel de destaque econômico e político que ocupa esta unidade federativa, quanto pela ousadia de seu conteúdo e a repercussão que causou. Elaborada pela CENP (Coordenadoria de Estudos e Normas Pedagógicas), tendo como assessores Marcos A. Silva e Déa Ribeiro Fénelon², a proposição paulista gerou uma discussão bastante intensa com uma forte polarização ideológica.

Para CORDEIRO (2000), a "proposta da CENP, em 1986, (...) representou um ponto de intersecção de todos os debates anteriores e uma espécie de ponto culminante das discussões do período". Foi proposto pela CENP o estudo em eixos temáticos para romper com a linearidade temporal e atender à multiplicidade do tempo histórico. O eixo principal seria o trabalho e os trabalhadores como construtores da nação, desdobrando-se em temas como "terra e propriedade", "cidade e fábrica: resistências cotidianas", etc. Para essa proposta curricular seria preciso conscientizar o aluno como agente do processo histórico, através do estudo das experiências sociais cotidianas. Defendia-se uma maior aproximação entre ensino e pesquisa e uma maior flexibilidade do currículo para atender às demandas de cada escola e à autonomia dos professores. A proposta trazia o objetivo explícito de colocar em xeque a democracia racial e a unidade nacional com o objetivo de "refletir como o racismo, os conflitos sociais, as diversidades regionais, as diferenciações culturais sempre foram camufladas no Brasil em nome da

\footnotetext{
2 Mais tarde, participou também, como assessor, Pedro Paulo de Abreu Funari, então professor do Departamento de História da UNESP, campus Assis.
} 
integração nacional, da harmonia social, dos interesses nacionais e da padronização cultural" (apud CORDEIRO, 2000, p. 180).

Contudo, a proposta da CENP não chegou a ser implantada. A reação intensa na imprensa com termos como 'barbarização ideológica', 'subversão', 'ignorância no poder', 'ideologização do ensino', etc. ${ }^{3}$ associaram o currículo de História a uma esquerda radical, inviabilizando o debate mais profundo sobre as questões pedagógicas e historiográficas que embasavam o projeto ${ }^{4}$.

Passados trinta anos, vem à tona, no país, uma nova proposta curricular, levantando novamente as opiniões da imprensa e debates políticos calorosos. 0 momento, coincidentemente, não poderia ser menos significativo. Um embate intenso sobre os rumos do país, como prolongamento do enfrentamento eleitoral de 2014, fez emergir discursos de viés antidemocrático, que, se existiam no século XXI brasileiro, estavam menos visíveis na primeira década do novo milênio. No campo da escolarização pública, estas vozes avançaram significativamente no impedimento das discussões das questões de sexualidade e gênero nas escolas e têm se articulado através de movimentos e slogans como o "Escola Sem Partido" que, semelhantemente aos antigos ideais da Doutrina de Segurança Nacional, busca impedir as discussões políticas e sociais em sala de aula.

Revisões curriculares no contemporâneo são comuns a quase todos os países. A aceleração do tempo, capitaneada pelo desenvolvimento tecnológico, e a instabilidade provocada por esta contemporaneidade precária (MIRANDA, 2009) fazem com que as incertezas pairem sobre os projetos educacionais de longo prazo. No mesmo caminho, os países estão constantemente repensando sua História e, por conseguinte, o espelho identitário que projetam.

\footnotetext{
3 Os artigos e editoriais de jornais foram publicados na Revista Brasileira de História de agosto de 1987.

${ }^{4}$ Vê-se, no entanto, a presença dos pressupostos que nortearam a proposta da CENP em currículos que circularam posteriormente, inclusive nos PCNs. Embora não tenha sido oficialmente colocada em prática, essa proposta, de fato, aglutina discussões de uma época importante para a identidade da disciplina escolar de História.
} 
O governo do Partido dos Trabalhadores, estabelecido a partir do ano 2003, representou uma mudança no que diz respeito ao investimento público e à concepção do papel do Estado na educação com aportes significativos em universidades e escolas técnicas federais, entre outros aspectos. Contudo, é forçoso reconhecer que, em relação à discussão curricular, houve elementos de continuidade das políticas públicas estabelecidas nos anos 1990 do século XX. Neste campo específico os projetos e investimentos que dizem respeito à questão da diversidade e da inclusão foram os que obtiveram maior ressonância.

A Base Nacional Comum Curricular (BNCC), portanto, seria a primeira grande intervenção curricular promovida após doze anos de governo. Nem por isto, necessariamente, representaria, por si só, uma ruptura com concepções anteriores. Fruto das discussões do Plano Nacional de Educação (PNE 2014) que estabeleceu 20 metas a serem cumpridas até 2020, a BNCC deveria conter direitos e objetivos de aprendizagem e desenvolvimento, unificando $60 \%$ do conteúdo escolar nacional. O restante seria definido localmente, levando em conta o contexto regional.

O projeto de uma Base Nacional aglutinou uma série de interesses difusos. Houve o envolvimento intenso da União Nacional dos Dirigentes Municipais de Educação (UNDIME) e do CONSED, o Conselho Nacional de Secretários de Educação. Para as discussões também foi convidada a Conferência Nacional dos Trabalhadores da Educação (CNTE). Um aporte significativo, contudo, foi dado pela criação do Movimento pela Base Nacional Comum da Educação em abril de 2013, a partir do "Seminário Internacional Liderando Reformas Educacionais". O Movimento pela Base foi formado por fundações e institutos mantidos pela iniciativa privada, ligados a ideais voltados à criatividade, tecnologia, empreendedorismo e, pelo menos no âmbito do discurso, da educação como ciência aplicada mais do que como práxis política 5 .

\footnotetext{
5 Do Movimento pela Base Nacional Comum participam a Fundação Lemann, o Instituto Inspirare/Porvir, o Instituto Península, a Fundação Roberto Marinho, o Instituto Ayrton Senna, o Instituto Natura, o Instituto Unibanco, personalidades políticas, gestores educacionais que tiveram grande destaque nos anos 1990, dentre outros sujeitos e instituições. Além do propósito explícito de melhorar a qualidade da educação e os índices educacionais, dois grandes interesses podem ser inferidos pelo avançar voraz de um movimento em torno de uma Base Educacional unificada. 1) 0 interesse ideológico de se fazer presente nas concepções curriculares que visam formar sujeitos criativos, com domínio tecnológico, adaptados ao modelo de sociedade global, alicerçada sobre o consumo incessante de novos bens e ideias; 2) O interesse mais pragmático na unificação curricular como uma unificação do mercado educacional nacional (e transnacional) para a realização mais
} 
Uma intensa campanha a favor da construção da BNCC emergiu dos órgãos públicos envolvidos e do Movimento pela Base. Referências de experiências, ditas bem-sucedidas, especialmente do Chile, dos EUA, da Inglaterra e da Austrália, passaram a ser veiculadas em vídeos e através de assessores estrangeiros contratados para compartilhamento de experiências ${ }^{6}$.

Contudo, antes e imediatamente depois da divulgação do texto preliminar, houve questionamentos sérios à necessidade de uma Base Comum e ao processo de construção da atual proposta. Dentre as principais críticas, levantadas por entidades importantes como a ANPED, estavam a pressa com que o processo foi desencadeado e a maneira como os professores da Educação Básica estariam sendo levados em conta neste processo, com a opção de aceitar ou discordar dos pequenos tópicos de direitos de aprendizagem. Questiona-se: por que não se tem pressa para outras metas do PNE que envolvem investimentos na condição de trabalho docente? Por que não discutir, também de maneira urgente, a viabilização dos investimentos necessários na formação inicial e na formação continuada, no salário inicial atrativo, em uma política de carreira estimulante, em melhores condições de trabalho, com um número menor de alunos por turma?7

Outra crítica muito forte se deu em relação à pretensão de transformar o currículo prescrito em currículo avaliado. É sabido, entre todos que trabalham com a escolarização, que entre o prescrito e o realizado, existem sujeitos e vontades. Entretanto, a avaliação externa exerce um peso de sobredeterminação da prática docente $^{8}$. Por isto, instrumentos externos de acompanhamento de aprendizagem precisam ser muito bem planejados, evitando que se tornem uma lista de produtos

imediata de comercialização de insumos didáticos, assessorias e gerenciamentos em parceria com a instituições públicas. Ressalva-se, neste caso, que o mercado educacional nacional já é semiunificado, extraoficialmente, pela tradição curricular. Em todo o caso, o que se constata é que estes agentes, ditos filantrópicos, já estão imiscuídos em muitos projetos públicos nacionais, estaduais e municipais, e sua participação na construção da Base Nacional é bastante explícita.

6 O espelhamento em experiências internacionais e a participação de consultores de outros países como Dave Peck, da organização britânica Curriculum Foundation, que, no ano de 2015, trabalhou no projeto de implementação ou reformulação de currículos nacionais no Reino Unido, Chile, Ruanda, Sudão do Sul, Zâmbia e Líbano - foi uma marca da construção da proposta da BNCC brasileira.

7 A supressão da autonomia dos professores (no diagnóstico de sua realidade), a falta de articulação com outras políticas e legislações educacionais (como as próprias Diretrizes Curriculares Nacionais para a formação inicial em nível superior, publicadas em 10 de julho de 2015) e os possíveis interesses privados envolvidos também estão entre as razões alegadas para a rejeição à BNCC.

8 A sobredeterminação ocorre por que a avaliação externa vem acompanhada da exposição pública dos resultados alcançados, muitas vezes com bonificações às escolas e docentes melhor sucedidos. 
desejados decorrentes de processos que indicam instrução padronizada mensurável, mais do que educação ${ }^{9}$.

De qualquer forma, é inegável a vinculação entre a proposta da BNCC e as avaliações externas (IDEB, PISA) realizadas pelo Estado brasileiro autonomamente ou em conjunto com outras instituições internacionais. A melhoria dos índices de aprendizagem está presente nos discursos de representantes públicos e instituições filantrópicas em defesa da BNCC. As próprias metas do PNE (ver o item 7.2, por exemplo) deixam esta vinculação muito clara. De fundo, portanto, também está em jogo o que se entende por aprendizagem.

A proposta preliminar da BNCC foi aberta para consulta pública em 16 de setembro de 2015 sem a disciplina de História. O texto de História já estava envolvido em alguma polêmica ainda antes da publicação. Duas semanas depois, o texto de História veio à tona e as repercussões foram imediatas. Diante das críticas, o ministro Renato Janine Ribeiro, recém-demitido devido a acordos políticos, revela que havia retido o documento de História por discordar de seus encaminhamentos e emite opinião pública: o texto da base "não pode descambar para a ideologia". A frase, infeliz, compreensível no contexto - e que, provavelmente, não expressa com exatidão o pensamento do ex-ministro com grande lastro intelectual - foi rapidamente apropriada por militantes de movimentos como o 'Escola sem Partido' na sua cruzada contra que entendem como um complô maquiavélico que se arquiteta nos espaços educativos brasileiros. Concomitantemente, e também de maneira imediata, o sociólogo Demétrio Magnoli e a historiadora Elaine Senise Barbosa traçaram críticas

\footnotetext{
${ }^{9}$ Ao envolver a mobilização da subjetividade, a aprendizagem da História pode ser avaliada, mas não facilmente mensurada. Se o produto final da consciência histórica é uma narrativa que conecta o presente e o passado e projeta um futuro, uma nova dimensão avaliativa também deve ser pensada. Mudanças estruturais da consciência histórica são visíveis apenas nos processos de longo prazo da aprendizagem histórica.
} 
representando uma outra vertente de pensamento para a qual o multiculturalismo é o novo 'perigo comunista' a ameaçar as bases da civilização ocidental ${ }^{10}$.

A partir daí, debates com maior profundidade e opiniões de historiadores e historioeducadores não cessaram de aparecer em redes sociais, blogs e imprensa, embora posicionamentos mais radicais, com nível baixo de análise, e instigação de ódio também surgissem, inclusive por parte de historiadores com prestígio nacional. Uma indignação mais frequente veio dos professores das áreas de História Antiga e Medieval que, interpretando que o papel das suas áreas diminuía drasticamente na proposta, construíram, através de associações, cartas de repúdio à BNCC.

Concomitantemente foram se tornando conhecidos os elaboradores da proposta de História divulgada pelo MEC. Estes publicaram pequenos textos em defesa das propostas. Ainda em 2015, diversos encontros para discutir a BNCC foram organizados por universidades, grupos de pesquisa e pela ANPUH (Associação Nacional de História). Alguns membros da comissão elaboradora participaram destes debates ${ }^{11}$. Na ANPUH-RJ as discussões, aparentemente, expuseram uma oposição, típica dos campos disciplinares e presente de longa data na área de História, entre os historiadores "puros" e os historioeducadores ${ }^{12}$.

As polêmicas geradas pelo texto preliminar de História na BNCC giraram em torno do que se entende por conteúdo substantivo, justamente por que estes, tomados como aprendizagem informativa, são o principal objetivo da abordagem tradicional e permanecem como meta de aprendizagem na prática da maioria das

\footnotetext{
10 Os textos de Magnoli e Barbosa, para além do alarmismo predominante, tocam em questões da temporalidade e da função das disciplinas escolares, temas que tentamos abordar mais adiante neste artigo.

${ }^{11}$ Infelizmente não pudemos participar destes encontros, que envolveram os elaboradores da BNCC, ocorridos principalmente nos grandes centros. O relato que fazemos é através das repercussões em textos e manifestos publicados.

12 O debate ideológico raso na imprensa e o confronto entre historiadores ligados à pesquisa do ensino-aprendizagem da História e os ditos historiadores documentais (velha oposição a que muitos buscam superar no contemporâneo) são os indícios de um dèjá vu que a discussão da BNCC nos desperta.
} 
instituições de ensino. Por isso, pensa-se currículo em História como uma mera disputa entre temas.

A proposta preliminar estabeleceu os seguintes 'conteúdos' anuais:

ENSINO FUNDAMENTAL: $1^{\circ}$ ANO - Sujeitos e Grupos Sociais; $2^{\circ}$ ANO - Grupos Sociais e Comunidades; $3^{\circ}$ ANO - Comunidades e outros lugares de vivências; 40 ANO - Lugares de vivências e relações sociais; $5^{\circ}$ ANO - Mundos brasileiros; 60 ANO Representações, sentidos e significados do tempo histórico; 70 ANO - Processos e Sujeitos; $8^{\circ}$ ANO - Análise de processos históricos; 90 ANO - Análise de processos históricos; ENSINO MÉDIO: $1^{\circ}$ ANO - Mundos ameríndios, africanos e afro-brasileiros; $2^{\circ}$ ANO - Mundos americanos; $3^{\circ}$ ANO - Mundos europeus e asiáticos (BRASIL, 2015).

Com algum esforço, pode-se inferir da listagem acima um pouco do caminho escolhido pelos elaboradores da BNCC para o ensino de História. Contudo, os títulos, especialmente do Ensino Fundamental, vagos ou imprecisos, são um dos fatores a gerar maior dificuldade na compreensão da proposta. O critério de organização - por procedimentos, por temas, por conceitos, por espaços culturais (no caso do Ensino Médio)? - não fica claro para o leitor.

Dentro dos tópicos anuais acima - que o texto preliminar da BNCC / História chama de "enfoques predominantes" - foram distribuídos os objetivos de aprendizagem a partir de quatro eixos que se repetem do início do Ensino Fundamental ao último ano do Ensino Médio: procedimentos de pesquisa; representações do tempo; categorias, noções e conceitos; e dimensões políticocidadãs. Não há, na introdução, um detalhamento destes eixos. Como veremos adiante, os autores utilizaram estas rubricas para lançar conteúdos substantivos que dão a impressão de uma distribuição aleatória.

De fato, na proposição dos objetivos/direitos de aprendizagem, a enunciação, construída pela BNCC, tentou unir na mesma frase os conhecimentos (conceitos, princípios, acontecimentos, etc.), traduzidos por substantivos, e as capacidades habilidades, expressas por verbos. A intenção, provavelmente (não sabemos se por decisão da equipe de História ou diretiva do projeto maior da Base), se deu para tentar atender ao princípio vygotskyano em que o desenvolvimento de capacidades cognitivas não ocorre independentemente dos conteúdos e das tarefas efetivamente desenvolvidas. Em que pese o propósito, o resultado não foi 
o ideal, pois nem os procedimentos, nem os conceitos, tampouco os conteúdos substantivos resultaram como objeto claro de aprendizagem.

Portanto, no primeiro contato e nas repercussões imediatas, juntaram-se à incompreensão de alguns interlocutores sobre os problemas mais profundos que envolvem a aprendizagem da História, dificuldades de redação e de clareza na proposta preliminar da BNCC, evidenciando problemas advindos do pouco tempo de discussão ${ }^{13}$ e da adequação a um esquema, previamente pensado, de descritores de direitos de aprendizagem que têm por objetivo ser referência para o acompanhamento e avaliação externa.

Para entender a proposta de História e suas repercussões é preciso ir além, e perceber que o texto da BNCC dialoga com uma realidade curricular, estabelecida pela tradição, em um formato que adquiriu estabilidade no início dos anos 1990 e, mesmo com revisões curriculares estaduais ou nacionais, permanece hegemônico. Trata-se de um currículo organizado de maneira cronológica baseado num princípio conhecido como história integrada que se repete nos diversos níveis de ensino ${ }^{14}$. Nesta organização, uma história da 'civilização' ocupa maior espaço no ambiente escolar, em detrimento da História do Brasil e da América.

Duas questões referentes a este currículo são enfrentadas pelos elaboradores da BNCC com maior atenção: a concepção de uma história única, válida para toda a humanidade e seu corolário o eurocentrismo ${ }^{15}$. No enfrentamento deste último, os autores da proposta defendem uma ênfase na História do Brasil como espaço político privilegiado da vivência dos estudantes. Dentro deste recorte intenta-se fazer um alargamento do reconhecimento da presença dos povos indígenas,

\footnotetext{
13 A comissão da área de História foi nomeada em junho de 2015.

${ }^{14}$ Do $1^{\circ}$ ao $5^{\circ}$ ano estuda-se a história regional e do Brasil de maneira cronológica; do $6^{\circ}$ ao $9^{\circ}$ ano trabalha-se "toda a história" da humanidade, organizada, mais uma vez, cronologicamente; e, finalmente, no Ensino Médio, estuda-se, novamente, "a história da humanidade, da pré-história aos dias atuais".

15 Basicamente, o espírito da civilização teria nascido no Oriente Próximo, ganhado seus fundamentos mais sólidos no mundo greco-romano e, retomado numa Europa das Luzes, chegou ao ápice espalhando-se pelo mundo. Em livros didáticos, mesmo propostas críticas ao capitalismo de origem europeia mantiveram esta estruturação.
} 
africanos e afro-brasileiros na história nacional. Já o Ensino Médio, além do destaque anterior, faz um recorte por continentes / áreas culturais, com destaque para o estudo da História da América no $2^{\circ}$ ano.

Ao menos desde as primeiras críticas ao evolucionismo, ainda no final do século XIX, a História perdeu seu $\mathrm{H}$ maiúsculo, no sentido de um relato único e linear e, da mesma forma, a partir da segunda década do século $X X$, o modelo ptolomaico da historiografia europeia (SPENGLER, 1973) passou a ser questionado. Ora, não existindo uma única história, a História escolar realiza escolhas, assim como o faz qualquer disciplina no nível universitário. Manoel Salgado Guimarães destaca a dimensão evocativa como matriz para a realização do trabalho do historiador. Trazendo o passado para o presente, os atos de evocação "assumem a dimensão de atos instituintes, condição de possibilidade, fundamentando as ações humanas" (GUIMARÃES, 2007, p. 29).

Neste sentido, a discussão provocada pelo texto da BNCC trouxe uma grande contribuição, ao deixar claro que é preciso abandonar a pretensão ou a ilusão de abarcar "toda a História" na Educação Básica. Isso se reforça ainda mais quando se pensa no tempo escolar. Não se trata apenas do número reduzido de horas semanais, mas diz respeito à concepção de como se produz aprendizagem. Muitos dos argumentos que defendem um currículo extenso baseado em trabalhar "toda a história", só podem fazer isto concebendo a "aula de História" como aula magna ou leitura seguida de exercício de livro didático. Imagina-se, com isso, alunos como ouvintes passivos.

Se, ao contrário, objetiva-se um outro perfil do estudante, com o professor propondo variadas formas de trabalho com debates, leituras de trechos de documentos escritos, imagens, etc. não é mais possível manter tantos conteúdos como possuem na atualidade muitos programas escolares. É a partir destas abordagens diferenciadas, demandando um investimento de precioso tempo escolar, que se dá a possibilidade de ressignificação dos conteúdos e de maior envolvimento dos estudantes. Os aspectos cognitivos do comportamento não se produzem à margem dos afetivos, sociais e motivacionais.

A Base precisa, então, ser a expressão de um currículo mínimo e terá que diminuir (ao contrário do que alguns estão defendendo) o seu rol de prescrições para que não se continue a obrigar os professores a um conflito de prioridades. A 
pressão das avaliações externas e seu rol extenso de conteúdos faz com que os professores tenham que optar entre 'falar' sobre tudo e desconsiderar os diversos processos de recepção e aprendizagem ou selecionar e fazer um trabalho mais significativo, correndo o risco de ser acusado de não ter cumprido todo o currículo. Vivemos em uma sociedade com excesso de informação, onde a experiência é cada vez mais rara, por falta de tempo (BENJAMIN, 1994; BONDÍA, 2002). Se queremos evitar um trabalho de acumulação de informações efêmeras nas escolas, em favor de uma aprendizagem significativa, temos que ter uma base que se atenha aos fundamentos do saber e da aprendizagem histórica.

A evocação de aspectos da História do Brasil deixou claro um posicionamento político dos elaboradores da Base, mas a justificativa ainda precisa ser melhor clareada, explicando a seleção de conteúdos através de critérios lógicos ou epistemológicos. Ao optar por processos sociais mais complexos, ao invés de um único grande relato, o texto preliminar da BNCC/História não deu conta de explicar o avançar entre uma série e outra. A pretensão de abarcar "toda a História" é um dos problemas centrais do currículo cronológico tradicional, o outro é a progressão entre as séries.

A organização cronológica tradicional não guarda nenhuma relação plausível com a maturidade cognitiva ou sociocultural dos estudantes. O único critério de anterioridade é a relação cronológica/causal da informação histórica. A priori não há nada que justifique que um aluno no $6^{\circ}$ ano deva estudar História Antiga e no 90 ano, História Contemporânea. O esperado seria que no 70 ano o estudante fosse capaz de rearticular os conceitos e as habilidades que aprendeu no $6^{\circ}$ ano, acrescentando novos saberes, estabelecendo, assim, uma espiralidade do conhecimento e possibilitando uma ampliação da sua consciência histórica.

A progressão se dá na direção da ampliação qualitativa do uso dos conceitos históricos, dos procedimentos meta-históricos, das competências cognitivas e sociais. Em busca de níveis mais amplos de abstração e generalização, é preciso propor situações cada vez mais complexas para os alunos. 


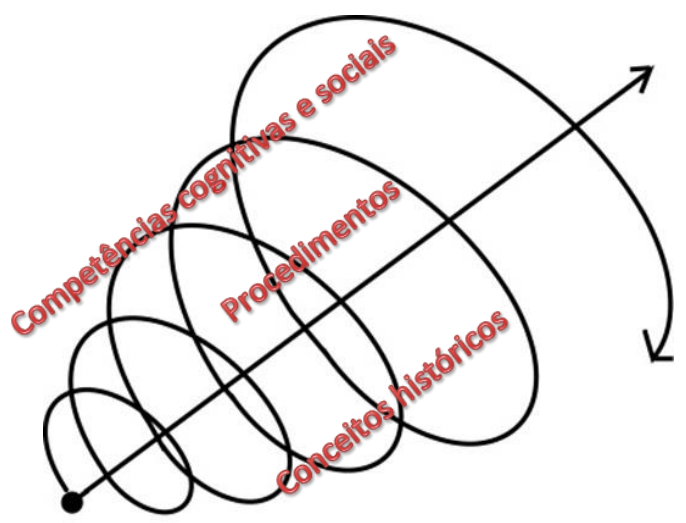

Imagem 1: Progressão do conhecimento histórico escolar. Fonte: elaborado pelo autor.

Na tentativa importante de fugir de uma história linear, o texto preliminar de História ficou muito aquém, até mesmo, da proposta geral da BNCC em relação à sequenciação lógica e progressiva da aprendizagem. Não se evidencia uma preocupação com um ordenamento dos conteúdos, dos conceitos, das habilidades e das competências. Alguns enunciados simplesmente se repetem, aparentemente a esmo, sem indicação de gradação de dificuldades.

Muitos dos embaraços no entendimento da proposta preliminar de História vêm, provavelmente, além do tempo exíguo de produção, da própria necessidade de adequação à concepção geral da BNCC e o modelo de descrição dos direitos de aprendizagem. Este é o caso dos eixos escolhidos para dar sentido à distribuição dos conteúdos: procedimentos de pesquisa; representações do tempo; categorias, noções e conceitos; e dimensões político-cidadãs. No texto preliminar, os 'conteúdos' dos eixos (que decorrem do modelo geral da base) não indicam coerência entre as finalidades atribuídas (o que se deduz, pois a introdução não explicitou as finalidades de cada eixo). Da mesma forma, não há um inter-relação clara entre os quatro eixos propostos. 
O que, por exemplo, a Base entende por Procedimentos de Pesquisa em História? Na maioria das séries constam dois itens importantes: trabalhar com fontes históricas e utilizar tecnologias para acessá-las. Em alguns raros momentos, a prescrição se aproxima dos quadros teóricos da Educação Histórica $(\mathrm{CHHI6FOA063})^{16}$, embora não traga nenhuma perspectiva de progressão em relação ao procedimento. Todavia, o que predomina como sentido para pesquisa é a atitude de encontrar informações sobre conteúdos substantivos.

A pesquisa é o procedimento central do espírito científico e, para muitos autores, também da aprendizagem escolar. Na escola tradicional confunde-se 'consulta' com 'pesquisa'. Pode-se consultar um dicionário, um site de referência na internet, etc., mas, 'consultar, copiar e entregar' não é pesquisa. A pesquisa está ligada à resolução de um problema através de um trabalho organizado, sistematizado. Numa pesquisa escolar há a possibilidade de uma mobilização de saberes diante de situações complexas. Como aprendizagem procedimental no ensino de História, a pesquisa reforça a percepção do saber histórico como um conhecimento indiciário que mobiliza uma série de habilidades e compreensões em torno da relação entre passado e presente.

O texto preliminar da Base, na maioria das vezes, apenas distribuiu conteúdos substantivos (este é o caso de todos os demais eixos) precedidos de verbos pouco significativos para o procedimento de pesquisa. Verbos como "reconhecer" (CHHI8FOA097; CHHI9FOA124) ou "identificar" (CHHI9FOA125) não indicam a realização de um procedimento de pesquisa. Da maneira como foi construído, o texto preliminar não torna a pesquisa um objeto de ensinoaprendizagem, ao contrário, reforça o senso comum em que pesquisar é apenas "encontrar informações" e a concepção de que a aprendizagem da História está ligada à aquisição cumulativa de conhecimento substantivo.

A mesma situação (de distribuição dos conteúdos substantivos, sem relação com a finalidade das rubricas) repete-se em todos os eixos do texto preliminar. $\mathrm{Na}$ rubrica "categorias, noções e conceitos" pouco ou nada se percebe sobre

\footnotetext{
16 Para não sobrecarregar o texto com citações da BNCC, utilizamos os códigos adotados pelo documento do MEC, publicado em (http://basenacionalcomum.mec.gov.br/documentos/BNCC-APRESENTACAO.pdf - acessado em 18/01/2016). Em geral, os códigos citados são exemplos pinçados de situações que se repetem ao longo do documento.
} 
aprendizagem conceitual ${ }^{17}$, discutida no ensino de História em longa data e bem tratada nos Parâmetros Curriculares Nacionais (BRASIL, 1998). Há conceitos e noções em todos os conteúdos históricos substantivos, é verdade, mas eles não são evidenciados no texto da Base e tampouco pensados numa aprendizagem progressiva.

Como mediadores da interpretação da realidade, os conceitos são essenciais à aprendizagem histórica, funcionando como ferramentas que podem ser operacionalizadas em situações diversas. O domínio de um conceito (e seu campo semântico) torna os objetos históricos inteligíveis. Não há na Base, entretanto, a indicação da mobilização de conceitos históricos como objeto de aprendizagem. Há pouca ou nenhuma conexão entre os eixos: em algumas séries, conceitos são apresentados na rubrica "dimensões político-cidadãs" ou "procedimentos de pesquisa" sem, ao menos, serem referenciados em "categorias, noções e conceitos". O conceito ou a categoria "populismo"18, por exemplo, não aparece nas "categorias noções e conceitos" a serem trabalhados no $2^{\circ}$ ano do Ensino Médio, mas na "dimensão política", os estudantes terão que discutir criticamente o populismo nas Américas (CHHI2MOA034). Há diversos momentos em que não se consegue identificar quais conceitos, noções ou categorias estão envolvidos no objetivo descrito (CHHI6FOA070).

No mesmo caminho, a aprendizagem do tempo histórico é objeto clássico de discussão no ensino de História, mas o eixo "representações do tempo" parece desconsiderar esta discussão e, mais uma vez, a rubrica serve para alocar conteúdos substantivos ou processo históricos. Não há progressão da aprendizagem das representações do tempo histórico, não se pensa a Educação Básica como um processo e cada série tem um fim estanque em si mesma.

As diferentes fases do ensino apresentam concepções bastante heterogêneas. Na primeira fase do Ensino Fundamental, os objetivos retomam um enfoque que está presente nos currículos brasileiros desde, pelos menos, os anos 1970: identificar mudanças e permanências, instrumentos mediadores (calendários, relógios) e estudar objetos ao longo do tempo. Há um objetivo que

\footnotetext{
17 Não entramos aqui na noção de 'conceitos de $2^{a}$ ordem' (meta-históricos) da Educação Histórica por entendermos que o eixo proposto na BNCC não intencionou esta discussão.

18 Conceito, aliás, questionado por parte da historiografia recente, o que chama atenção para outra dificuldade da BNCC: a historicização dos conceitos e a atualização historiográfica.
} 
propõe à criança construir uma concepção crítica das datas comemorativas, meta que procura enfrentar os meandros da tradição escolar, mas que ficaria melhor dirigida à formação dos professores.

$\mathrm{Na} 2^{\mathrm{a}}$ fase do Ensino Fundamental, a intenção de conhecer medidas consagradas de tempo se mantém no $6^{\circ}$ ano. No $7^{\circ}$ ano há um único objetivo cuja dimensão de aprendizagem temporal nem de longe fica em primeiro plano (CHHI7FOA08). No $8^{\circ}$ e no $9^{\circ}$ ano, a enunciação muda novamente. Para o $8^{\circ}$ ano são sete objetivos iniciados por "conhecer e compreender" períodos e processos históricos. No 90 ano são três direitos iniciados por "reconhecer o século $X X$ como...." e um "compreender o século XX como...". No $1^{0}$ ano do Ensino Médio retoma-se a temporalidade como contagem do tempo - embora enfatizando a diferença cultural - e o mesmo objetivo do Ensino Fundamental de crítica às datas comemorativas. Nas demais séries, a mesma situação de clareza da proposta se repete, levando o leitor a questionar o porquê daquele objetivo ter sido alocado nesta rubrica e não nas outras e, da mesma forma, por que outros conteúdos também não são representações do tempo (CHHI1MOA006; CHHI2MOA021; CHHI2MOA022; CHHI3MOA041).

Finalmente temos o eixo das "dimensões político-cidadãs". Embora a ligação do conhecimento histórico com as questões de identidade e, consequentemente, com política e cidadania sejam bastante evidentes, esperar-se-ia que um documento curricular que apresenta um eixo específico para esta área intentasse deixar ainda mais destacados os valores e posicionamento éticos individuais e coletivos envolvidos com os estudos dos processos históricos. Esta dimensão enfatizaria, portanto, a consequência do trabalho com conteúdos substantivos, conceitos e procedimentos para a relação entre passado, presente e perspectiva de futuro, iluminando possibilidades de orientação da vida prática. É justamente neste momento que ficaria mais claro que o estudo de alguns aspectos do passado, de maneira significativa, em sua relação com a vida do estudante, funciona como mediador semiótico dos juízos morais que, situados socioculturalmente, orientam as ações humanas no mundo.

No entanto, não é isto que acontece no texto da BNCC. Na maioria das vezes, a dimensão político-cidadã é um outro conteúdo, à parte do que se está trabalhando nas dimensões de pesquisa, tempo e conceitos. Por exemplo, no 30 
ano do Ensino Médio, no eixo dos conceitos, não se destacam os conceitos de nazismo, fascismo ou stalinismo, nem totalitarismo, mas na dimensão políticocidadã, pede-se para: "discutir e posicionar-se sobre os Direitos Humanos, as pluralidades e as exclusões ao longo do século XX, a partir de processos históricos tais como o fascismo, o nazismo e o stalinismo" (CHHI3MOA052). O mesmo se pode dizer em relação ao estudo do Código de Defesa do Consumidor (CHHI4FOA044) e os direitos da criança (CHHI4FOA043) para referenciar um nível de ensino diferente.

Há problemas mais difíceis de solucionar decorrentes do modelo curricular da Base, estruturado visando um processo de avaliação do cumprimento das metas. O formato de descritores de objetivos/direitos de aprendizagem seria mais adequado para uma organização por nível/fase de ensino do que para um currículo seriado. Por isso, talvez, o texto preliminar de História oscila entre objetivos muito amplos - e outros imprecisos - para uma única série (CHHI5FOA053; CHHI5FOA054; CHHI6FOA073; CHHI6FOA076; CHHI7FOA085; CHHI9FOA133; CHHI3MOA043; CHHI3MOA056).

Mas, o problema maior está na sinalização de uma concepção de aprendizagem em História. Muitos dos verbos utilizados na BNCC repõem o objetivo tradicional: saber informações sobre a História. Há tempos se sabe que aprender História vai muito além disso. Se o objetivo final é uma orientação nova no presente ligada a uma perspectiva de futuro, o conteúdo tem que ser trabalhado no sentido de provocar experiência. Se assim não o for, pode-se acumular acervos de informação histórica, sem se inserir nas mudanças temporais, o que significa a indiferença ou um posicionamento como 'terceira pessoa'.

Para evitar a exterioridade do saber histórico em relação ao sujeito, é preciso estar atento à relevância dos temas escolhidos para o entendimento do mundo contemporâneo. Mas ainda é necessário ir além, na formulação dos encaminhamentos ou objetivos. Não se pode apenas tomar o conteúdo informativo e acrescentar um verbo, transformando-o em objetivo como uma substância a ser 
consumida. A informação histórica é parte fundamental, mas ela sozinha não garante a aprendizagem.

O texto preliminar da base oscila entre as duas formas de razão pedagógica: uma que faz pensar e outra que transmite o já pensado. É difícil a superação desta situação, dentro de um modelo engessado de direitos de aprendizagem. Uma maior variação dos verbos utilizados e uma atenção à relação entre o enunciado e a aprendizagem que, de fato, se almeja podem ser uma possibilidade.

Para Gimeno Sacristán, "existe uma especial conexão entre as crenças epistemológicas dos professores e os estilos pedagógicos que adotam" (2000, p. 180). Na descrição de conteúdos substantivos evidencia-se uma epistemologia implícita (por que ou para que se estuda; como se estuda, etc.). Neste sentido, se a BNCC quer significar um avanço em relação à concepção tradicional de aprendizagem, tem que propor - e penso que o texto preliminar já aponta para isso - uma história não convencional gerando problematização, desequilíbrio, saída da zona de conforto das interpretações pré-estabelecidas, da trivialidade. É assim que se busca o efeito desestabilizador que toda a aprendizagem histórica pode promover, possibilitando uma maior abertura dos indivíduos à experiência, combatendo a indiferença que grassa em muitas práticas escolares, ajudando muitos estudantes ávidos - a recente ocupação de escolas no estado São Paulo mostrou isso - de participar na construção de significados para a experiência escolar e para sua própria existência.

Como projeção dos ideais e sonhos de toda uma sociedade, a educação escolar é um campo em disputa. Neste sentido qualquer reforma curricular será vista, no mínimo, como incompleta e lacunar. Não há como esperar um consenso, ainda mais em um país de gigantescas proporções como o Brasil. Mas o texto final da BNCC pode ser uma tentativa, dentre diversas opções, de avançar, para aqueles que acreditam que o conhecimento histórico é fator decisivo para a construção de identidades individuais e coletivas.

O debate sobre a Base já teve o mérito de desestabilizar a pretensa universalidade da História única, linear, colaborando na percepção de que os 
conteúdos históricos são selecionados a partir de critérios lógicos e políticos. Escolhas se impõem pelo tempo escolar e pela certeza de que a ideia de abarcar "toda a história" é irreal e sua permanência é decorrente de uma concepção construída no século $X I X$ e início do século $X X$, com objetivos que não são mais defensáveis racionalmente no mundo contemporâneo.

A repercussão do texto preliminar de História da BNCC trouxe à tona velhos problemas que giram em torno do Ensino de História, desde quando se constituiu como campo disciplinar, e alguns novos dilemas próprios do século XXI. Se atualmente temos a clareza de que não são quaisquer experiências do tempo (ou conteúdos históricos) que podem se tornar fatores da orientação prática e da autocompreensão (RÜSEN, 2011), as escolhas precisam ser as mais racionais possíveis $^{19}$. E esta racionalidade precisa ser compartilhada coletivamente. O texto preliminar carece de precisão e da ideia de currículo mínimo (formação dos fundamentos). A maneira como foi escrita gera inúmeras dubiedades em relação ao que se espera da aprendizagem da História. Os objetivos / direitos descritos oscilam entre especificidades, prescrição de interpretações fechadas e amplitudes exageradas para um currículo seriado.

A importante estratégia de significação partindo do presente terá que ser mais bem esclarecida na introdução. É nesta introdução que o diálogo com o professor da Educação Básica necessita estar presente, como uma maneira de estabelecer uma relação com o código disciplinar da história, uma negociação com a tradição escolar. No mesmo caminho, é importante evidenciar um diálogo com a produção historiográfica mais recente.

O novo texto precisará prestar mais atenção à progressão, assim como pensar melhor a adequação entre idade e desenvolvimento cognitivo dos estudantes. Também há necessidade de esclarecer melhor a finalidade dos eixos propostos e a inter-relação entre eles. Unidade, coesão de propósitos e progressão entre os níveis de ensino poderá ser uma importante sinalização do entendimento da função do Ensino de História na Educação Básica.

\footnotetext{
19 Por exemplo, a escolha por eventos traumáticos ou passados dolorosos que significam uma ferida aberta, não resolvida, no presente. Neste sentido, a base buscou incluir a experiência negativa da escravidão (indígena e africana), por exemplo, e contrabalançar com a ideia de 'protagonismo'. Nos demais "conteúdos", todavia, não aparenta uma reflexão mais profunda na seleção e na ênfase do enunciado. Veja-se o caso da última ditadura militar, já negligenciada para o "último minuto do segundo tempo" nos currículos cronológicos, e muito pouco evidenciada na BNCC.
} 
No momento em que finalizamos este artigo, temos a informação que a ANPUH passou a ser considerada uma interlocutora importante para a construção da Base e está realizando debates em suas regionais a fim de organizar uma proposta nacional. Só por esta mobilização a discussão da BNCC já está valendo a pena. Novos consultores e leitores críticos estão se juntando à equipe original para a reformulação do texto preliminar. Fazemos votos que a equipe ampliada encontre o melhor caminho para iluminar o papel do conhecimento histórico na formação de crianças e jovens. Papel este que é social, dinâmico e conflitivo, mas que pode também oferecer alguma estabilidade no meio da tempestade do mundo contemporâneo, quando se incorporam as transformações não apenas como contingência, mas como fruto de decisões humanas.

\section{Fontes}

ANPED. Associação Nacional de Pós-Graduação e Pesquisa em Educação. Moção Contrária à Base Nacional Comum Curricular. Disponível em: http://www.anped.org.br/. Acesso em 20/01/2016.

ANPUH-BRASIL - Associação Nacional de História. http://site.anpuh.org/. Acesso em 20/01/2016.

ANPUH-BRASIL - Associação Nacional de História. http://site.anpuh.org/. Carta de Repúdio à BNCC produzida pelo Fórum dos Profissionais de História Antiga e Medieval. Acesso em 20/01/2016.

BRASIL. Secretaria de Educação Fundamental. Parâmetros curriculares nacionais: terceiro e quarto ciclos do ensino fundamental: História. Brasília: MEC/SEF, 1998. $108 \mathrm{p}$.

BRASIL. Base Nacional Comum Curricular. Disponível em: http://basenacionalcomum.mec.gov.br/\#/site/inicio. Acesso em 20/01/2016.

BRASIL. Plano Nacional de Educação 2014-2024. Lei no 13.005, de 25 de junho de 2014, que aprova o Plano Nacional de Educação (PNE) e dá outras providências. Brasília: Centro de Documentação e Informação. Coordenação Edições Câmara, 2014.

MAGNOLI, D.; BARBOSA, E. S. História sem tempo. O Globo online, 08/11/2015. MAGNOLI, D.; BARBOSA, E. S. Proposta do MEC para ensino de história mata a temporalidade. Folha de São Paulo online. Disponível em http://www1.folha.uol.com.br/ilustrissima/2015/11/1703011-proposta-do-mecpara-ensino-de-historia-mata-a-temporalidade.shtml. Acessado em 20/01/2016

MOVIMENTO PELA BASE NACIONAL COMUM. http://movimentopelabase.org.br/. Acesso em 20/01/2016 
RIBEIRO, R. J. Postagem na rede social Facebook. 8 de outubro de 2015.

VAINFAS, R. Nova face do autoritarismo. O Globo online, 05/12/2015. http://oglobo.globo.com/opiniao/nova-face-do-autoritarismo-18225777.

Acessado em 20/01/2016

\section{Referências}

ALBUQUERQUE JR. D. M. Fazer defeitos nas memórias: para que servem o ensino e a escrita da história? In: GONÇALVES, M. de A.... [et al.] (Org.). Qual o valor da história hoje? Rio de Janeiro: Editora FGV, 2012. p. 21-39.

BENJAMIN, Walter. Magia e Técnica, Arte e Política. Ensaios Sobre Literatura e História da Cultura. Obras Escolhidas. São Paulo, Brasiliense, 1994.

BONDÍA, J. L. Notas sobre a experiência e o saber de experiência. Revista Brasileira de Educação. n. 19. Jan/Fev/Mar/Abr 2002,

CANDAU, Vera Maria. Cultura(s) e Educação. Entre o crítico e o pós-crítico. Rio de Janeiro: DP\&A, 2005.

CARRETERO, M. Documentos de identidade: A construção da memória histórica em um mundo globalizado. Porto Alegre: Artmed, 2010.

CORDEIRO, J. F. A história no centro de debate: as propostas de renovação do ensino de História nas décadas de 70 e 80. São Paulo: Cultura Acadêmica, 2000.

CUESTA FERNÁNDEZ, R. Sociogénesis de una disciplina escolar: La Historia. Barcelona: Pomares-Corredor, 1997.

GUIMARÃES. M. L. S. O presente do passado: as artes de Clio em tempos de memória. In: ABREU, M.; SOIHET, R.; GONTIJO, R. (Org.). Culturas políticas e leituras do passado: historiografia e ensino de história. Rio de Janeiro: Civilização Brasileira, 2007. p. 25-39.

LARROSA, J. Pedagogia Profana: danças, piruetas e mascaradas. Belo Horizonte: Autêntica, 2006. 208p.

MIRANDA, D. S. Contemporaneidade Precária. In: NOVAES, Adauto (Org.). A Condição Humana: as aventuras do homem em tempos de mutações. Rio de Janeiro: Agir; São Paulo: Edições SESC SP, 2009. p. 7-8.

MORENO, J. C. História e Ensino Fundamental: formando os fundamentos. Anais do XI Encontro Regional da Associação Nacional de História, 2008.

MORENO, J. C. Quem somos nós? Apropriações e Representações Sobre a(s) Identidade(s) Brasileira(s) em Livros Didáticos de História (1971-2011). Jundiaí: Paco Editorial, 2014.

MORENO, J. C. Revisitando o conceito de identidade nacional. In: RODRIGUES, C. C.; LUCA, T. R. de; GUIMARÃES, V. (Org.). Identidades brasileiras: composições e recomposições. São Paulo: Cultura Acadêmica, 2014. p. 07-29. 
MORENO, J. C.; RANZI, S. M. Avaliação em História nas Séries Iniciais. Curitiba, UFPR; Brasília: MEC, 2005.

RÜSEN, J. Aprendizagem histórica: esboço de uma teoria. In: Aprendizagem histórica: fundamentos e paradigmas. Curitiba: W. A. Editores, 2011. p. 69-112.

RUSEN, J. Como dar sentido ao passado: questões relevantes de meta-história. História da Historiografia, n. 2, mar./2009, p. 163-209.

SCHMIDT, M. A.; BARCA, I.; MARTINS, E. R. (Org.). Jörn Rüsen e o ensino de História. Curitiba: Ed. UFPR, 2010. p. 51-78.

SIMAN, L. M. de C. Representações de Memórias Sociais Compartilhadas: Desafios para os Processos de Ensino e Aprendizagem da História. Cad. Cedes, Campinas, vol. 25, n. 67, p. 348-364, set./dez. 2005.

SPENGLER, O. A decadência do Ocidente: esboço de uma morfologia da História Universal. Rio de janeiro: Zahar, 1973.

VYGOTSKY, L. S. A formação social da mente. São Paulo: Martins Fontes, 1978.

Recebido em 05 de Janeiro de 2016. Aprovado em 25 de Julho de 2016. 